\title{
Empowering discourse: discourse analysis as method and practice in the sociology classroom
}

Titus Hjelm*

School of Slavonic and East European Studies, University College London, Gower Street, London WCIE 6BT, UK

(Received 14 August 2012; final version received 22 February 2013)

Collaborative learning and critical pedagogy are widely recognized as 'empowering' pedagogies for higher education. Yet, the practical implementation of both has a mixed record. The question, then, is: How could collaborative and critical pedagogies be empowered themselves? This paper makes a primarily theoretical case for discourse analysis (DA) as a form of classroom practice that provides a structured framework for collaborative and critical pedagogies in higher education, with a special reference to sociology classroom practice. I develop a tripartite scheme for building a framework for sociological imagination that is, first, sensitive to the discursive aspects of social reality (learning about DA). Second, I illustrate the use of DA as pedagogical tool and classroom practice (learning with DA). Third, I discuss how discourse analytical ideas can be used in evaluating classroom interaction and how these reflexive insights can be used to enhance student empowerment (learning through DA).

Keywords: discourse analysis; collaborative learning; critical pedagogy; sociology; empowerment

\section{Introduction}

There is an almost universally shared (hegemonic, if you will) agreement about the benefits of student-centered learning in higher education. Student empowerment is the buzzword. On the one hand, this can mean conceptualizing the student as a coconstructor of knowledge - instead of 'didactic authoritarianism' (Northedge 2003, 169 ) - thus making the learning experience more student-led. On the other hand, 'empowerment' can be defined more broadly as learning critical thinking and essential citizenship skills. In educational parlance, student empowerment can be achieved through collaborative learning and critical pedagogy.

Although these two are not an exhaustive list of empowering learning approaches, they have become trademark labels in higher education pedagogy. Yet, the results of research on the implementation of collaborative and critical pedagogies have been ambiguous (e.g. Chouliaraki 1998; Mayes 2010). The potential failure of 'empowerment', 'collaborative learning', and 'critical pedagogy' is demonstrated by Mayes' (2010) study of the discursive construction of identity and power in a 'critical classroom'. Using field notes, interviews, transcripts of student-teacher writing conferences and learning materials from an English course using a critical pedagogy

*Email: t.hjelm@ucl.ac.uk 
approach, she analyzed how, despite the democratic aims of critical pedagogy, the course failed to redistribute power to students and ended up being teacher-directed. The buzzwords end up being hollow much too often. The question, then, is: How could collaborative and critical pedagogies - pedagogies of 'empowerment' - be empowered themselves?

This paper makes a primarily theoretical case for discourse analysis (DA) as a form of classroom practice that provides a structured framework for collaborative and critical pedagogies in higher education. I will discuss the use of DA on three different levels of learning: (1) learning about DA, (2) learning with DA, and (3) learning through DA. ${ }^{1}$ I will first discuss the basic assumptions of DA and the challenges of building a learning framework that is sensitive to the discursive aspects of social reality (learning about DA). Second, I will illustrate the use of DA as pedagogical tool and classroom practice (learning with DA), that is, using DA for analyzing primary source texts collaboratively with students. In this section, I will situate DA as classroom practice in the broader framework of constructionist and collaborative learning theories (e.g. Bruffee 1993; Bruner 2000; Gergen and Wortham 2001; Wortham and Jackson 2008). Third, in the section on learning through DA, I will discuss how discourse analytical ideas can be used in evaluating classroom interaction by turning the focus from primary texts to the collaborative analysis process itself, i.e., examining how the collaborative analysis in the learning with phase actually works. These reflexive insights can be used to enhance critical and collaborative learning and student empowerment in the tradition of critical pedagogy (e.g. Freire 1970; Giroux 1983, 1988; Fairclough 1989; Bernstein 1990). Finally, before concluding, I will discuss some questions arising from a discourse analytical approach to classroom practice.

Although I would like to think that the principles of the scheme outlined above are applicable to classroom practice regardless of discipline, I explore the above questions specifically in the context of my own specialization, sociology. Sociology is about seeing with a new pair of eyes; unlearning and relearning much of what we take for granted about society. There is, however, an inbuilt potential for frustration in learning sociology. Students can perceive sociological theory in particular (Holtzman 2005; Pedersen 2010) as irrelevant because of its apparent incompatibility with everyday experience, and, as a result, they can resist engaging with it, in and outside the classroom. Both the richness and challenge of learning and teaching sociology lies undoubtedly in this 'double hermeneutic' (Giddens 1993) nature of sociological knowledge. C. Wright Mills (1959) coined the now ubiquitous term 'sociological imagination' which - instead of plain hoarding of 'facts' or reliance on logical reasoning alone - has become a guiding principle in discussing pedagogical practice in sociology (Kebede 2009; Huisman 2010). Collaborative and critical pedagogies have been offered as tools for developing the sociological imagination (Pedersen 2010; Braa and Callero 2006; Fobes and Kaufman 2008), but as I argue below, DA can further empower these empowering pedagogies.

Finally, a caveat or a 'reading guide' is in order: all of the sections draw from courses that I have taught, but in an illustrative, rather than systematic, way. The current three-stage approach emerged during these courses, and working through a teacher training program in the institution that $I$ teach in has prompted me to better articulate my thoughts and to begin to orient my pedagogical practice along the lines presented here. However, the current paper should be considered first and foremost a 
theoretical outline and a blueprint for a holistic approach that needs to be systematically tested in subsequent research.

\section{Learning about DA}

I have applied the tripartite schema in two undergraduate area studies courses I have taught in the last 2 years. Partly this has been possible because the groups have been small and I have been familiar with the students. In that intimate setting, traditional lecturing, or even 'active learning' seemed superficial, so I enquired whether the students would be interested in trying out a project where we would collaboratively analyze primary sources and - if possible within the timeframe - actually write up our research into a proper academic journal article. The students liked the idea, so despite this not being part of the original curriculum design - we embarked on the little article project 'experiment' that is the background of this article.

The students on these courses come mainly from a language background, with little or no methodological training. As the main focus of the courses is national identity or, more accurately, the social construction of national identity, DA - which I have employed in my own research - seemed like a perfect fit for a collaborative analytical framework. Key works in sociological identity theory (e.g. Jenkins 2008) and DA (e.g. Wodak et al. 2009; Mole 2007) supported my case.

The 'problem' with DA is, however, that it is much more than a research 'technique' in a narrow sense. In fact, as Derek Edwards and Jonathan Potter (1992, 11) argue, calling the approach analysis has 'the unfortunate consequence that it is sometimes treated as a method only, a technique something on a par with an experiment or a questionnaire'. They go on to say that 'there is more than a methodological shift at work; there is some fairly radical theoretical rethinking' (Edwards and Potter 1992, 11; cf. Mills 2004, 117; Bloor and Wood 2006, 54). Thus, the first challenge for me as a teacher was how to make students best learn about DA - how to avoid the aversion to theory mentioned above and how to "lend" students the capacity to frame meanings they cannot yet produce independently' (Northedge 2003, 172).

As to the basics of DA, discourse analysts generally define 'discourse' as a way of speaking that does not simply reflect or represent social entities and relations, but constructs or 'constitutes' them (Fairclough 1992, 3). All descriptions of the world are by definition partial and the variability of discourse itself is an indicator of the constructed nature of social life. Also, importantly, discourse itself is seen as a form of social practice, contributing both to the reproduction of society and to social change (Fairclough 1992; Potter 1996, 105). Edwards and Potter (1992) talk about the 'action orientation' of discourse, that is, how things are done with discourse.

The idea of social construction and the performative function of discourse challenge students' common sense assumptions about the social world and thus require initiation into the 'specialist discourse' of DA. I will not repeat Northedge's (2003) brilliant outline of a teacher-led approach, except to say that in my own teaching, I quickly noticed that starting with the abstract, theoretical discourse was a mistake. The students found the textbook (Locke 2004) difficult and counterintuitive - something that I as someone immersed in the framework of DA could not anticipate. 
Northedge (2003, 175-176) suggests that one way of enabling the students access to specialist meanings is to start with the familiar. So, I asked the students to first use DA to analyze sources they were personally interested in. I think this was helpful because when working with familiar material (e.g., an episode from a favorite TV series, newspaper texts), there is less temptation to impute problems in interpretation to insufficient knowledge of the content/substantive topic. To put it the other way around, the distinctiveness of DA is made more apparent by making the students reassess their 'common sense' interpretations of familiar texts. As I had expected, there was still some resistance to DA after these initial analyses, but group discussion of the problems helped us - I included - clarify what the 'point' of DA was. In other words, learning about DA is teacher-led in the sense that although the students were doing DA, the texts were familiar and were used primarily to prime the students into the specialist discourse of DA.

In fact, a level of collaborative learning is needed at this stage as well: Because DA offers a very broad 'toolkit' for analyzing textual data - so much so that paying attention to all aspects outlined in the literature so far would make practical research impossible - discourse analysts know which 'tools' are needed only after familiarizing themselves with both the theoretical background assumptions and their choice of data. While the choice of data will necessarily be guided by the topic of the course in question, this choice can and should be a collaborative endeavor (see below).

\section{Learning with DA}

In line with the premises of my approach, discussions of sociological pedagogy often highlight the importance of doing sociology as the best way to learn sociology (Huisman 2010; Atkinson and Hunt 2008; Halasz and Kaufman 2008). These approaches encourage students to 'move away from a right/wrong orientation of learning and [to] construct knowledge rather than seeking it from the instructor as the "expert" (Atkinson and Hunt 2008, 4). Although truly collaborative learning is possible only if the students are properly embedded in the specialist discourse (learning about DA), collaboration is considered crucial to learning by doing, which I call learning with DA.

Collaborative learning - widely discussed in education research - emphasizes the constructed nature of the social world and offers intersubjective dialogue as an alternative to top-down passing on of knowledge to individuals, or approaches that see knowledge construction as an individual, cognitive process (Bruner 2000; Gergen and Gergen 2001). This basic idea has been implemented in reorganizing learning in settings ranging from primary (Rogoff, Turkanis, and Bartlett 2001) to higher education (Bruffee 1993). Collaboration is also the key to implementing the principles of critical pedagogy (Braa and Callero 2006; Fobes and Kaufman 2008). As Mayes $(2010,192)$ notes, 'students will not be empowered by implementing a curriculum that extols an ideology of empowerment unless the students are actively involved as agents in the process'. Further, critical pedagogy has rarely provided practical tools for implementing the critical theory framework (Mayes 2010, 192). This is where learning with DA comes in.

Although I discuss this in the next section, it is important to note at this point that what I refer to learning with DA should not be confused with research on classroom roles and interaction that has used DA (Rogers 2004; Rogers et al. 2005; 
Chouliaraki 1998; Mayes 2010). For example, despite the promising title Using Discourse Analysis to Improve Classroom Interaction, Rex and Schiller's book (2009) is yet another example of how to use DA to analyze classroom interaction, not how to implement DA as learning practice. While obviously important, these approaches contribute to what I refer to as learning through DA, not to learning with DA. ${ }^{2}$

What does learning with DA look like, then? Although every course with learning with DA element is by definition unique, there are several issues that will come up in most cases in the sociology classroom. While drawing from the courses mentioned above, the points below are a combination of an ideal typical process and an ethnographic account of what actually happened.

\section{Negotiating breadth and topic}

Although all of the students were happy with the idea of doing a focused collaborative research project based on DA, we decided that the project should not take up the entire course so that the breadth of the substantive topic (society and culture in one European country) would not be sacrificed. In negotiating the terms of agreement, I hoped to avoid the situation described by Mayes (2010), where, despite an aim to share agency with students, empowerment was effectively restricted by adherence to preconceived criteria of teacher directedness and assessment. I did suggest the topic for the project (religion in parliamentary discourse in the country studied) and the sources (transcripts of MPs speeches in parliament), ${ }^{3}$ and these were mutually agreed upon.

\section{Contextual reading}

Most discourse analysts would agree with the definition of discourse as 'text in context' (Wodak 2008, 5). If the subject matter of the analysis is something familiar to the students (e.g. student's talk about campus relationships), reading about the context is obviously less important, although even then it is always useful to review any previous research on the topic. In the case of a more remote social context, as in the parliamentary discourse case, the next step for our group was to familiarize ourselves with as much background information on the legislative process, political culture, and religion in the target country as possible in the timeframe we had. Although necessary for the analysis, this is also the stage where the 'collaborative' part is most fragile as there can be a tendency to trust the teacher as the source of how things 'really' are.

\section{Choosing the 'toolkit' and collaborative analysis}

This is the heart of the learning with DA stage. It is also the part of the process that is most reflexive because (a) as explained above, the discourse analytical tools used in analysis need to be weighed against the research question and data, and (b) sharing of agency requires building the rules of collaboration from the ground up every time. In other words, there are few ground rules on how to choose your discourse analytical toolkit and conduct collaborative analysis. For the political discourse project, I disseminated my own unpublished paper on DA, a different version of which was later published in an edited research methods volume (Hjelm 2011). Based 
on that paper, we decided to concentrate on three aspects of the texts: First, we discussed what I have referred to as contextualization, that is - roughly - the main themes of discussion. Second, we analyzed the rhetorical devices outlined by Potter (1996) that are used to buttress contextualization and undermine competing contextualizations. Finally, we looked at ways in which the parliamentary discourse could be said to work ideologically, that is, how discourses 'contribute to the production, reproduction or transformation of relations of domination' (Fairclough 1992, 87). This is where the interests of critical pedagogy and Critical Discourse Analysis (CDA) converge (Fairclough 1995, 219-232).

The practical collaboration was organized so that we all read a portion of the source text and made preliminary analyses by ourselves, after which in the next class we discussed our interpretations and negotiated a shared interpretation. Although DA can never claim be 'objective', analyzing discourse collaboratively offers the chance to check one's interpretations against fellow analysts' interpretations, pointing out subjective biases (Nikander 2008). Again, pedagogically speaking, this is a potentially fragile process because of the institutionalized inequality of teacher-student roles. However, in the context of a critical pedagogy, collaborative DA has the potential to allow students to come to their own understanding of this aspect of the classroom and its relation to broader issues of structural inequality (the learning through phase).

In general, the students appreciated the DA approach the more they used it to engage with primary text material. In some cases, a disciplinary identity was used as rhetorical tool for claiming incompetence ('I'm a historian, I don't think I've understood this right'), sometimes the overall theoretical baggage was considered problematic. However, despite these hedging 'strategies', the students were generally positively surprised when they realized that their interpretations - when made within the agreed collaborative DA framework - were as 'proper' results of DA as anyone else's.

\section{Collaborative writing}

There is plenty of research and theory on collaborative writing, especially in the emerging fields of 'academic literacies' and 'writing across the curriculum/writing in the disciplines' (e.g. Lea and Street 1998; Russell et al. 2009; Monroe 2002; Bruffee 1993), so much so that it is not necessary to recount the basic approaches here. At the time of the research project, I was only superficially familiar with this literature, but the fact that a lot of the approaches spring from the same constructionist framework - i.e. writing as identity construction (Ivanic 1998) - as DA makes collaborative writing a 'natural' part of the holistic approach to DA as classroom practice. Ideally, following David Russell, 'Writing becomes so embedded in activity that it tends to disappear as an object of conscious attention. As it becomes routine, we forget that we once had to learn to write in specialized ways' (Russell 2005).

Unfortunately, the first collaborative writing project never advanced beyond the first stages as the students graduated and did not pursue further studies in the same institution, which might have motivated them to work on the text beyond the undergraduate degree. The second one is on hold and will be continued with only some of the original participants, for the same reasons. This creates a dilemma for timing DA-based projects: On the one hand, in terms of continuity and opportunity 
to finish writing the research while still doing a degree, it would be preferable to slot DA courses early in the students' degree - first half of the second year, for example. On the other hand, in terms of better learning skills and receptiveness to collaborative projects, the final year seems like a better option. This of course then risks the situation that I have just described. Although conceived here as part of undergraduate learning, the approach is wholly compatible with graduate learning. Here, the pros and cons are balanced as well: students may be better equipped to participate in collaborative learning and writing, but the hectic pace of Master's degrees (at least in the British system) is a challenge for any collaborative writing project.

Still, my experience is that students' attitude toward writing differs when they are writing for publication and not just for credits. Although many students have been 'published' in the form of blogs, for example, in ways unthinkable 20 years ago, the printed (and reviewed!) word still holds a special fascination. Obviously, not all DA projects end up in top sociology journals - most will not - but the sense that there is potentially an original research article in the making does seem to create an extra incentive.

\section{Learning through DA}

If learning with DA is still an unexplored area in education research and pedagogy of sociology, what I refer to as learning through DA is a fairly established field. In a comprehensive review, Rogers et al. (2005) assess the different ways in which DA and critical DA in particular - has been used in education research. Although there is considerable variety in the field, DA has been widely used 'to make sense of the ways in which people make meaning in educational contexts' (Rogers et al. 2005, 366; see also Luke 1995-1996; Hicks 2005).

Learning through DA means directing a critical gaze at the learning with DA process itself. The twist is that instead of being an outsider, the analyst in this case is using DA to analyze the practice of doing DA with students (learning with DA) reflexively. There are basically two ways of doing this: parallel and longitudinal.

\section{Parallel analysis}

By 'parallel analysis', I mean a practice where the interaction during the learning with DA stage is analyzed between the analyses of primary texts. This is the ideal situation from a critical pedagogy and CDA perspective: The students and tutor engage in critical reflection of the process while doing analysis. Needless to say, this is challenging for all participants. The analysis of primary material is interrupted by critical 'meta-analysis' and potential role problems need to be solved. The discourse and/or conversation analysis (CA; see below) of classroom interaction does, however, provide a rigorous way of assessing power relations on the micro-level and as such is perfectly suited for a curriculum emphasizing empowerment.

\section{Longitudinal analysis}

Practically speaking, it can be difficult to implement a full-blown, three-stage DA practice within institutional and other constraints - it certainly was impossible in the 
timeframe of a one-term course, in our case. If this is not possible, the next best thing is for the tutor to analyze the interaction in order to identify problem points and improve classroom practice for the next cohort - similarly to Mayes' study (2010). Again, the 'validity' - the word should be understood in a particular sense within a qualitative framework - of the analysis can be improved by having a second analyst work on the classroom interaction data. The problem is, of course, that the current course participants will not benefit from the analysis and the learning through is limited to the teacher.

$D A$ or $C A$ ? The line between DA and what is commonly known as CA is fuzzy (see Wooffitt 2005). As a broad generalization, it could be said that DA is more interested in the context of language use, whereas CA looks at the dynamics of micro-interaction, but as Fairclough (1995) and others have shown, the actual procedures of analysis can be very similar. Analyzing the meaning of classroom interaction is important, of course, but it is exactly the attention to micro-detail that makes CA or conversation-focused DA attractive in the learning through DA stage. A good example is turn-taking, that is, how participants control conversations by taking turns in speaking (see Fairclough 1989, 134-135). In fact, educational events (from early childhood to higher education) are often used as a prime example of analyzing the ways in which interruptions, questions, and prompts create power imbalances (e.g. Chouliaraki 1998, Mayes 2010). Analysis of turn-taking and other techniques drawn from CA can be very helpful in identifying classroom roles and constructing an open, reflexive, and empowering learning environment. This is still in progress for the courses that I have used as an example. The requirements of both parallel and longitudinal analyses pose serious questions for the timing - within a degree and within an academic year - of courses with a DA element.

\section{(Some) challenges}

\section{Class size}

The first question that comes to mind about DA as classroom practice is: does it work only in small seminar-type settings? While it is obvious that small groups are ideal for a DA approach, there is no reason why it should not work with bigger groups. A class of 20, for example, could be divided into four or five smaller groups each that tackle a particular primary text. Managing bigger groups is more challenging, of course, and there is danger that if and when the tutor cannot participate equally in all groups, s/he assumes a role of arbiter between groups, thus sacrificing the democratizing role of being just another analyzer.

\section{The 'free rider' problem}

This, again, is a very common problem not unique to a DA approach. In fact, any active learning methods are prone to experience 'free riding' in some form (e.g. Pedersen 2010). However, learning with DA can be, it could be argued, even more demanding than 'traditional' active and collaborative learning methods. It is quite possible that all students on a course might be resistant to an approach that requires them to spend what can be perceived as extra energy compared to a traditional lecture format (see e.g. Gibbs 1992). In light of the critical pedagogy ideas discussed 
above, it is therefore very important to discuss the requirements and demands - but also the benefits - of a course employing a DA approach. I have done this in the very beginning of the course in question, following the 'rules' of democratic discussion outlined by Brookfield and Preskill (1999). Nevertheless, since first running my courses using DA, I have had a 'contingency plan', an alternative course outline, just in case students on a particular year are not responsive to the idea. Empowerment cannot be forced upon people, after all.

\section{Institutional constraints and 'constructive alignment' issues}

Most importantly, individual higher education courses are always embedded in curricula and other institutional contexts. The method of delivery is constrained and - one would hope at least - enabled by this institutional framework. Here, I am particularly concerned with what Rust $(2007,230)$ calls 'constructive alignment', that is, a clear linkage between stated objectives, learning activities, and assessment. While it could be argued that a DA approach adds value to a (non-method) course, it is more difficult to reconcile it with traditional assessment methods. Assessment by exam sounds hardly 'constructive' in this case. But then the question is: How do I assess coursework (essays) where I am one of the contributors? Since undergraduate courses often have (at least in the UK) quite strict and institutionally prescribed assessment requirements, this is a real problem in applying a DA approach to curricular learning.

In my area studies courses, I asked the students to write assessed essays about the contextual reading topics they did before the actual analysis of primary data. This worked quite well. The same should not be attempted with actual analyses of data, however. First, there is a problem of reflexivity mentioned above: if the tutor really is one of equal analysts, there is no way of distancing oneself from the student's written work. Second, if the students' analysis is assessed, the tutor explicitly puts him- or herself in a superior position, thus negating the idea of empowerment. This, of course, is a recurrent problem with any attempt at democratic assessment.

\section{Conclusion: DA as method and practice in the sociology classroom}

While there are no doubt further criticisms and questions to be posed to the DA as method and practice approach I am advocating here, my argument here is that bringing DA out of the isolation of method courses into a central aspect of curriculum design is a step toward a more engaging and critical learning process. 'Empowerment', as understood and envisioned here, means providing the students with a democratic role in collaboratively co-constructing sociological knowledge in the classroom. Further, along the lines of critical pedagogy, empowerment refers to the creation of broader sociological and social consciousness, which 'helps people see how their choices can either perpetuate injustice and continue silence or contribute to growth and even emancipation' (Brookfield and Preskill 1999, 6).

The above process of learning about, with, and through DA can be implemented across the disciplines whenever texts are a source of knowledge, but is, I think, particularly significant for sociology. DA provides a lens for 'seeing through the sociological eye' (Ruane and Cerulo 2008) and while it is and should not be an exclusive lens, the double aspect of the approach - as pedagogical tool and method 
of evaluation - is a powerful way of introducing what is special about sociology, that is, the sociological imagination. Most importantly, DA as classroom practice can shorten the gap between undergraduate and research degrees by focusing on doing sociology, instead of learning about it. As such, it enables a first-hand experience of the sociological imagination and provides building blocks for the creation of a sociological identity early on in the career path.

I hope to have demonstrated that DA as classroom practice enables the creation of a structured learning environment which can further empower the empowering approaches of collaborative learning and critical pedagogy, and which provides a unique approach to evaluating the reflexivity of the learning process. As mentioned in the beginning, the above should be read as a chronicle of a work in progress and a blueprint that needs to be refined through practical application. In a true constructionist vein, I would like to think my contribution as an opening of a dialogue rather than the last say in the matter.

\section{Acknowledgements}

I would like to thank the organizers of UCL's Postgraduate Certificate in Learning and Teaching in Higher Education programme, especially Holly Smith, Jane Hughes, and Colleen McKenna for valuable comments and support. A big thank you also to Jim Spickard, Steven Engler, Richard Mole, Ruth Wodak and the anonymous reviewers for their comments and advice. Needless to say, all remaining errors are mine alone.

\section{Notes}

1. I have used 'learning' instead of 'teaching' on purpose because the constructionist framework of DA emphasizes the interactional nature of knowledge. The teacher and student are, therefore, both learning in the process (Freire 1998, 29-48; Wortham and Jackson 2008).

2. To be fair, Rex and Schiller - and much of the education research employing DA - discuss using DA in elementary school settings, whereas the learning with DA approach advocated here is appropriate only in a higher education context.

3. The analysis thus included a translation element, which complicates things, but in the interests of space I will not go into that here.

\section{References}

Atkinson, M. P., and A. N. Hunt. 2008. "Inquiry-Guided Learning in Sociology." Teaching Sociology 36 (1): 1-7. doi:10.1177/0092055X0803600101.

Bernstein, B. 1990. "Class Codes and Control." The Structuring of Pedagogic Discourse. Vol IV. London: Routledge.

Bloor, M., and F. Wood. 2006. Keywords in Qualitative Methods: A Vocabulary of Research Concepts. London: Sage.

Braa, D., and P. Callero. 2006. "Critical Pedagogy and Classroom Praxis." Teaching Sociology 34: 357-369. doi:10.1177/0092055X0603400403.

Brookfield, S. D., and S. Preskill. 1999. Discussion as a Way of Teaching: Tools and Techniques for University Teachers. Buckingham: The Society for Research into Higher Education \& The Open University Press.

Bruffee, K. A. 1993. Collaborative Learning: Higher Education, Interdependence, and the Authority of Knowledge. Baltimore: Johns Hopkins University Press.

Bruner, J. 2000. The Culture of Education. Cambridge, MA: Harvard University Press.

Chouliaraki, L. 1998. "Regulation in 'Progressivist' Pedagogic Discourse: Individualized Teacher-Pupil Talk.” Discourse \& Society 9 (1): 5-32. doi:10.1177/0957926598009001001. 
Edwards, D., and J. Potter. 1992. Discursive Psychology. London: Sage.

Fairclough, N. 1989. Language and Power. London: Longman.

Fairclough, N. 1992. Discourse and Social Change. Oxford: Polity Press.

Fairclough, N. 1995. Critical Discourse Analysis. London: Longman.

Fobes, C., and P. Kaufman. 2008. "Critical Pedagogy in the Sociology Classroom: Challenges and Concerns." Teaching Sociology 36 (1): 26-33. doi:10.1177/0092055X0803600104.

Freire, P. 1970. Pedagogy of the Oppressed. London: Continuum.

Freire, P. 1998. Pedagogy of Freedom. Oxford: Rowman and Littlefield.

Gergen, K. J., and M. Gergen, eds. 2001. Social Construction: A Reader. London: Sage.

Gergen, K. J., and S. E. F. Wortham. 2001. "Social Construction and Pedagogical Practice." In Social Construction in Context, edited by K. J. Gergen, 115-136. London: Sage.

Gibbs, G. 1992. Improving the Quality of Student Learning. Bristol: Technical and Educational Services Ltd.

Giddens, A. 1993. New Rules of Sociological Method. 2nd ed. Princeton: Princeton University Press.

Giroux, H. A. 1983. Theory and Resistance in Education. South Hadley, MA: Bergin and Garvey.

Giroux, H. A. 1988. Schooling and the Struggle for Public Life: Critical Pedagogy in the Modern Age. Minneapolis, MN: University of Minnesota Press.

Halasz, J., and P. Kaufman. 2008. "Sociology as Pedagogy: How Ideas from the Discipline Can Inform Teaching and Learning." Teaching Sociology 36: 301-317. doi:10.1177/ $0092055 X 0803600401$.

Hicks, D. 2005. "Discourse, Learning, and Teaching." Review of Research in Education 21: 49-95.

Hjelm, T. 2011. "Discourse Analysis." In The Routledge Handbook of Research Methods in the Study of Religion, edited by M. Stausberg and S. Engler, 134-150. London: Routledge.

Holtzman, M. 2005. "Teaching Sociological Theory through Active Learning: The Irrigation Exercise." Teaching Sociology 33: 206-212. doi:10.1177/0092055X0503300207.

Huisman, K. 2010. "Developing Sociological Imagination by Doing Sociology: A Methodsbased Service-learning Course on Women and Immigration." Teaching Sociology 38 (2): 106-118. doi:10.1177/0092055X10364013.

Ivanic, R. 1998. Writing and Identity: The Discoursal Construction of Identity. Amsterdam: John Benjamins.

Jenkins, R. 2008. Social Identity. 3rd ed. London: Routledge.

Kebede, A. 2009. "Practicing Sociological Imagination Through Writing Sociological Autobiography." Teaching Sociology 37: 353-368. doi:10.1177/0092055X0903700404.

Lea, M. R., and B. V. Street. 1998. "Student Writing in Higher Education: An Academic Literacies Approach." Studies in Higher Education 23 (2): 157-172. doi:10.1080/0307507 9812331380364.

Locke, T. 2004. Critical Discourse Analysis. London: Continuum.

Luke, A. 1995-1996. "Text and Discourse in Education: An Introduction to Critical Discourse Analysis." Review of Research in Education 21: 3-48. http://www.jstor.org/stable/1167278.

Mayes, P. 2010. "The Discursive Construction of Identity and Power in the Critical Classroom: Implications for Applied Critical Theories." Discourse \& Society 21 (2): 189210. doi:10.1177/0957926509353846.

Mills, C. W. 1959. The Sociological Imagination. New York: Oxford University Press.

Mills, S. 2004. Discourse. 2nd ed. London: Routledge.

Mole, R., ed. 2007. Discursive Constructions of Identity in European Politics. Basingstoke: Palgrave.

Monroe, J. 2002. Writing and Revising the Disciplines. Ithaca: Cornell University Press.

Nikander, P. 2008. "Constructionism and Discourse Analysis." In Handbook of Constructionist Research, edited by J. A. Holstein and J. F. Gubrium, 413-428. New York: The Guilford Press.

Northedge, A. 2003. "Enabling Participation in Academic Discourse." Teaching in Higher Education 8 (2): 169-180. doi:10.1080/1356251032000052429.

Pedersen, D. E. 2010. "Active and Collaborative Learning in an Undergraduate Sociological Theory Course." Teaching Sociology 38 (3): 197-206. doi:10.1177/0092055X10370119. 
Potter, J. 1996. Representing Reality: Discourse, Rhetoric, and Social Construction. London: Sage.

Rex, L. A., and L. Schiller. 2009. Using Discourse Analysis to Improve Classroom Interaction. New York: Routledge.

Rogers, R. 2004. "An Introduction to Critical Discourse Analysis in Education." In An Introduction to Critical Discourse Analysis in Education, edited by R. Rogers, 1-18. Mahwah, NJ: Lawrence Erlbaum.

Rogers, R., E. Malancharuvil-Berkes, M. Mosley, and G. O'Garro Joseph. 2005. "Critical Discourse Analysis in Education: A Review of the Literature." Review of Educational Research 75: 365-416. doi:10.3102/00346543075003365.

Rogoff, B, C. G. Turkanis, and L. Barrett, eds. 2001. Learning Together: Children and Adults in a School Community. New York: Oxford University Press.

Ruane, J. M., and K. A. Cerulo. 2008. Second Thoughts: Seeing Conventional Wisdom Through the Sociological Eye. 4th ed. Los Angeles, CA: Pine Forge Press.

Russell, D. R. 2005. "Writing in the Disciplines and 'The Institutional Practice of Mystery." Paper presented at the Institute of Education, University of London, London, November 2005.

Russell, D. R., M. Lea, J. Parker, B. Street, and T. Donahue. 2009. "Exploring Notions of Genre in 'Academic Literacies' and 'Writing across the Curriculum': Approaches across Countries and Contexts." In Genre in a Changing World: Perspectives on Writing, edited by C. Bazerman, A. Bonini, and D. Figueiredo, 459-491. Colorado: WAC Clearinghouse/ Parlor Press.

Rust, C. 2007. Towards a Scholarship of Assessment. Assessment \& Evaluation in Higher Education 32: 229-237. doi:10.1080/02602930600805192.

Wodak, R. 2008. "Introduction: Discourse Studies - Important Concepts and Terms." In Qualitative Discourse Analysis in the Social Sciences, edited by R. Wodak and M. Krzyzanowski, 1-29. Basingstoke: Palgrave.

Wodak, R., R. De Cillia, M. Reisigl, and K. Liebhart. 2009. The Discursive Construction of National Identity. 2nd ed. Edinburgh: Edinburgh University Press.

Wooffitt, R. 2005. Conversation Analysis and Discourse Analysis: A Comparative and Critical Introduction. London: Sage.

Wortham, S. E. F., and K. Jackson. 2008. "Educational Constructionisms.” In Handbook of Constructionist Research, edited by J. A. Holstein and J. F. Gubrium, 107-128. New York: The Guilford Press. 